\title{
Nursing Evaluation of Risk Factors Associated with Surgical Site Infection Among Coronary Artery Bypass Graft Patients at King Abdulaziz University Hospital
}

\author{
Norah Bakheet Al Johani \\ Specialized Nurse \& Coordinator of Adult Cardiac Surgery, Cardio Surgery Department, King Abdulaziz University, Jeddah, KSA \\ Email address: \\ NALJOHANI0023@stu.kau.edu.sa \\ To cite this article: \\ Norah BakheetAl Johani. Nursing Evaluation of Risk Factors Associated with Surgical Site Infection Among Coronary Artery Bypass Graft \\ Patients at King Abdulaziz University Hospital. American Journal of Nursing Science. Vol. 6, No. 3, 2017, pp. 165-175. \\ doi: 10.11648/j.ajns.20170603.14
}

Received: February 2, 2017; Accepted: February 15, 2017; Published: March 11, 2017

\begin{abstract}
Surgical site infection is postoperative wound infection that occurs after surgery. The complications in the acute care facilities with up to $60 \%$ of surgical site infection cases estimated to be preventable by using evidence-based practice. Not with standing the advances in the coronary artery bypass graft, the rising prevalence of surgical site infection has become a primary concern in the infection control practices. The current study amid to evaluate the risk factors associated with the surgical site infections among coronary artery bypass graft patients and, to assess nurses compliance to bundle care to prevent surgical site infection. The study followed a quantitative, retrospective design and was carried out in King Abdulaziz University Hospital in Jeddah city. All sample $(n=120)$ coronary artery by-pass graft patient's record complied between January 2011 to December 2013.The study revealed statistically significant results between the preference of surgical site infection and demographic factor e.g. body mass index, patient risk factors such as diabetes type1 and 2, selected pre-operative factors e.g. Methicilin-resistant staphylococcus aurous, postoperative factors e.g. rewiring, dressing, ventilation and low cardiac output. This study established that the compliance with the bundle was proven to be effective in reducing risk factors to surgical site infection however nurses adherence to surgical site infection bundle care were incomplete and required more enforcement to comply. Based on the finding, the investigator recommended that nurses should be aware of the importance of adhering to surgical site infection bundles. Nurses should not only be educated on the importance of the bundles, but on how effectives apply the bundles at different stages.
\end{abstract}

Keywords: Surgical Site Infection, Bundles, Coronary Artery Bypass Graft

\section{Introduction}

The growing aging population, coupled with unprecedented lifestyle changes has influenced the rising prevalence of heart diseases. Coronary artery disease or ischemic heart disease are now the leading causes of morbidity and mortality worldwide. The World Health Organization (WHO)has reported that coronary artery diseases affect more than seven million people annually on a global scale in 2008 [1]. On the other hand, the world health organizationhas also identified coronary artery diseases as the principal cause of mortality in the Kingdom of Saudi Arabia. For instance, the Saudi ministry of health reported that cardiovascular diseases accounted for about $19 \%$ in (2007),
$22 \%$ in (2006), and $20 \%$ in (2005) of all deaths in the kingdom [2]. Coronary artery bypass graft has emerged as one of the principal surgical procedures across the globe. The American Heart Association reported that 242, 000 patients underwent 416, 000 coronary artery bypass graft surgeries in the United States in 2009 [1].Nevertheless, coronary artery bypass graft operations are prevalent among Saudi males than females because the latter population has high smoking percentages. In the same, coronary artery bypass graft surgeries are common in elderly patients who are increasingly referred for revascularization [2]. Conversely, the elderly patients undergoing coronary artery bypass graft often times report less successful revascularization, as well as adverse outcomes [3]. 
Significant advances in the recent past have transformed heart surgery from a prohibitive to a commonplace procedure. In essence, Coronary artery bypass graft has now become a more accepted and much safer surgical procedure. Coronary artery bypass graft entails the replacement of a clogged heart vessel with a vein or an artery that has been harvested from another body part. The vein or artery is then grafted to the obstructed coronary artery; hence, bypassing the blocked section of this artery [4]. The majority of patients undergoing Coronary artery bypass graft often have excellent results. Approximately $85 \%$ of these candidates experience a significant reduction of symptoms, reduced risk for future cardiac arrests and lowered chances of mortality within ten years after the bypass surgery [5].Coronary artery bypass surgeries have traditionally involved the open harvesting of veins, which entail making an extended incision on the patient's leg from the ankle to the groin. However, vein grafting as been associated with increased risk of wound infections and long-term chronic pain [6].

The limitations of open harvesting led to the development of minimally invasive vein harvesting technique that uses an endoscope, which is now more preferred to open harvesting. Endoscopic harvesting of vein graft reduces infection, shortens hospitalization days and lessens pain. Consequently, the number of Coronary artery bypass graft has declined significantly from 519, 000 in 2000 to 300,000 infections in 2012 [7].Surgical site infection is defined as those infections manifesting within 30 days of a surgical procedure (or within one year if an implant is left in place during the procedure) and affecting either the incision or deep tissue at the operation site[8]. Not with standing, in advances in Coronary artery bypass graft surgery, the primary concern is the rising prevalence of surgical site infection. Recent study findings surgical site infection are the most common Hospital Acquired Infections accounting for $31 \%$ of all infections among hospitalized patients [9, 5]. There have been noteworthy advances regarding infection control practices. Such practices have included improved ventilation of the operating room, enhanced sterilization techniques, availability of antimicrobial prophylaxis, and developed surgical techniques. Nonetheless, surgical site infection remain one of the principal causes of morbidity and mortality, in addition to prolonging hospitalization [4]. Surgical site infection accounts for 3\% of mortality rate, while $75 \%$ of deaths associated to surgical site infection are linked to the infections directly [9]. However, one of the strategies of reducing surgical site infection is continuous surveillance coupled with regular feedback to surgeons regarding the appropriate information on surgical site infection cases [6]. An appropriate surveillance program encompasses efficient surveillance techniques, as well as the categorization of surgical site infection rates based on the risk factors that influence their development [9].

\subsection{Aim of Study}

- 1. To evaluate risk factors associated with surgical site infection among coronary artery by-pass graft patients.
- 2. To assess nurses compliance to bundle care to prevent surgical site infection.

\subsection{Research Questions}

- 1. What are the risk factors associated with development of surgical site infection among Coronary artery bypass graft patients at King Abdulaziz University Hospital?

- 2. What is the nurse's compliance to bundle care to prevent surgical site infection?

\subsection{Problem and Significance of Study}

The incidence rate of surgical site infection is low (between $1 \%$ and $3 \%$ ), it is regarded as a challenging complication and crucial area of research. The consequence of complications that arise from surgical site infection is mortality of between $8.6 \%$ and $47 \%$ [10].Understanding the causes and risk factors for surgical site infection with coronary artery bypass graft may provide information that could be used to alert nurses and other health care practitioners on patients that are at risk and areas that should be addressed in order to optimize preoperative as well as postoperative health status of patients with coronary artery bypass graft. Surgical site infection can have significant effect on patient's quality of life. They are considered to be an important contributing factor to prolonged hospital stay of patients. In addition, surgical site infection following cardiac surgery are considered a significant cause of mortality, morbidity and enormous financial burden to the families of the patients as well as to health care systems [11].

The classification of risk factors as: individual risk factors which include high body mass index, female gender, diabetes mellitus, smoking, chronic obstructive pulmonary disease, and low ejection fraction; and surgical factors which include prolonged aortic cross-clamp time and total operative time, use of temporary pacing wires, re-operation for cardiac tamponade and necessity for intra-arterial balloon pump [11].

Nursing Role According to Bundle Care

Preoperative Phase:

- 1. The nurse should educate the patient about the importance of preventing surgical site infection and gives the "Reducing surgical site infections" patient education pamphlet.

- 2. The nurse has to explain to the patient about the importance of the preoperative shower and gives the patient the $4 \%$ chlorhexidine shower packet with two soap-envelops and the educational material [12].

Preoperative Morning of Admission Phase:

- 1. Patients who did not shower with the chlorhexidine packet or those with a body mass index greater than 30 are washed with $2 \%$ chlorhexidine impregnated cloths.

- 2. Hair removal by clipper at the site of surgical is performed and is done outside of operation room.

- 3. If the patient is hypothermic upon arrival in the pre-op area, the perioperative nurse will provide the warmed blankets or apply a forced-air warming device [13]. 


\section{Intraoperative Phase:}

- 1 . If the patient is hypothermic, the circulating nurse adjusts the operation room temperature according to the protocol and uses air warming blanket, if not initiated in the pre-op area. According to protocol, the patient's temperature is monitored every 15 minutes until it is $>$ $96^{\circ} \mathrm{F}$, then the room temperature is reduced.

- 2. The antibiotic is infused within 60 minutes necessary to incision; and

- 3. Chlorhexidine-alcohol skin preparation is performed by the surgical assistant with a 3-minute dry time [12, 13].

Postoperative Phase:

- 1. On the morning of postoperative day 2, the sterile dressing is removed by the surgeon.

- 2. The patient showers with $4 \%$ chlorhexidine once the dressing is removed, but if unable to shower, bathes with $2 \%$ chlorhexidine cloths daily and is instructed to continue for two weeks after discharge.

- 3. Hand hygiene is important and should be strictly followed by patients, visitors and providers [9, 12].

\section{Theoretical Framework}

With regards to application of evidence based practices in clinical practice, the Association for Professionals in Infection Control competency model (APIC) for infection preventions was chosen by the investigator for the importance of the model in infection prevention.

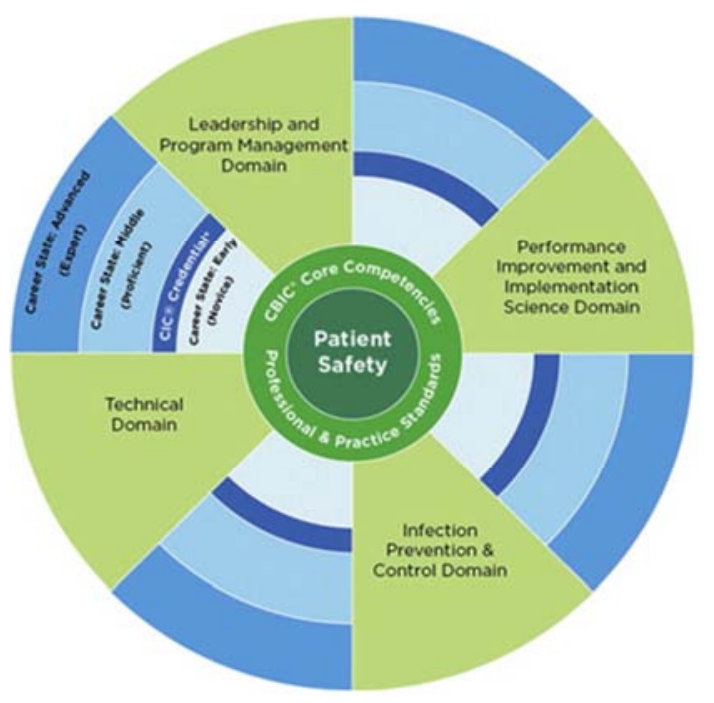

Figure 1. Association for Professionals in Infection Control.

The research study has focused on risk factors among coronary artery graft patients and within the risk factors is the likelihood of infection at different domains of Association for Professionals in Infection Control. The domains are four in number, where the prevention and control domain is considered as one domain. All these domains are directed towards the core competency of ensuring the patient's safety within the hospital. The leadership domain in the model has a basis influence rather than authority. This means that leadership skills are directed towards collaboration, followership, program management, communication, and critical thinking [14].

All these skills can be directed towards ensuring the safety of the coronary bypass patient within the hospital by influencing actions and decisions affecting the patient's safety directly and indirectly. Like the leadership domain will follow, all other domains of the model are directed towards positively influencing the patient's safety while admitted in the hospital. The model is, therefore, largely applicable to this research based on the fact that it is directed towards reduction of risk factors in coronary artery by-pass graft patients.

With relation to King Abdulaziz University Hospital, each of those domains should address the specific area of clinical needs of specialty. On the leadership domain, management and King Abdulaziz University Hospital should focus on collaboration measures that promote better health outcomes. The collaboration implies that the management has to seek the inclusion of practicing specialized cardiac doctors and nurses in the hospital policy and regulation formation. On performance improvement, quality management should be a core concern issue at the hospital so they guide the practice in cardiac unit and the health professionals need to adhere to the established quality standards that improve performance of nurses in cardiac units. Quality circles can be used to develop ways to improve performance at critical care units at university hospital. As it comes to infection prevention and control domain, King Abdulaziz University Hospital has an infection control committee charged with specialized epidemiologist and infection control nurses to oversight the establishing measures to infection prevention and control. The committee should ensure the utilization of evidence based practices to provide informed decisions directed towards infection control and prevention policies. The technological domain requires that the institution applies the highest standards of technological equipments directed towards better health outcomes, applying negative pressure modes to control infection in patients' rooms. All domains of the model are directed towards positively influencing the patient's safety while at the hospital.

\section{Methodology}

\subsection{Design}

The study adopted a quantitative retrospective study approach to evaluate risk factors associated with surgical site infection among coronary artery by-pass graft patients and to assess nurses compliance to bundle care to prevent surgical site infection.

\subsection{Setting}

Data collected from the department of medical records at King Abdulaziz University Hospital in Kingdom of Saudi Arabia.

\subsection{Subjects}

The sample size was $(n=120)$ coronary artery by-pass graft 
patients records complied between January 2011 to December 2013.

\subsection{Instrumentation}

The investigator used the surgical site infection bundle implemented at King Abdulaziz University Hospital and generally used for prevention of all surgical infection. Few modifications were done by the investigator to suite implementation of surgical site infection bundle for Coronary artery by-pass graft patients. Surgical site infection bundle can be broadly classified into three parts, part I demographic data included body mass index, age, nationality, and gender, part II patient's risk factors include smoking, chronic obstructive pulmonary disease, hypertension, peripheral vascular disease and diabetes mellitus type 1 and 2, and part III surgical site infection bundle in 5 phases (preoperative factors, intraoperative factors, postoperative factors, wound infections and management of outcomes).

\subsection{Data Analysis}

The Statistical Package for Social Science (SPSS version 22) was used to check, enter and analyze the collected data.There was two sheets, one for the cases and the other for the controls, each having columns for the various risk factors. The Frequency distribution table was then obtained for each sheet and the percentage of the patients who developed surgical site infection or those who did not develop surgical site infection was calculated for each of the risk factors.

\subsection{Ethical Approval}

The study contained obtaining information from medical record of coronary artery bypass graft patients therefore no harm involved and no direct intervention or procedure on the patients was used. Ethical approval attended from biomedical ethics unit at King Abdulaziz University and given to the director of medical records department, at King Abdulaziz University where confidentiality of data is reserved and destroyed after completion of research.

\section{Results}

\subsection{Demographic Characteristic of the Patients Included in the Study $n=120$}

Table 1. Showing demographic characteristic.

\begin{tabular}{llllllll}
\hline & & Male & \multicolumn{3}{c}{ Female } & \multicolumn{2}{c}{ Total } \\
\hline \multirow{3}{*}{ Nationality } & & $\mathbf{\%}$ & $\mathbf{\%}$ & $\mathbf{n}$ & $\mathbf{n}$ & $\mathbf{\%}$ & $\mathbf{n}$ \\
\cline { 3 - 8 } Total & Saudi & 11.5 & 0.0 & 0 & 12 & 11.5 & 12 \\
& Non- Saudi & 88.5 & 100 & 16 & 108 & 88.5 & 92 \\
& & 100 & 86.7 & 13.3 & 16 & 120 & 104 \\
\hline
\end{tabular}

A total of 120 coronary artery bypass graft cases were identified. Among the identified cases, 104 cases, equivalent to $86.7 \%$ were males while 16 cases or $13.3 \%$ were females.
Saudi patient's male were to be $11.5 \%$, and female $0.0 \%$, the non-Saudi patient's male $88.5 \%$, and females $100 \%$.

Distribution of Studied Samples According to Mean, Standard Deviation of Age and Body Mass Indexn=120

Table 2. The mean and standard deviation of age and Body mass index.

\begin{tabular}{lllll}
\hline & Female & \multicolumn{3}{l}{ Male } \\
\cline { 2 - 5 } & Mean & SD & Mean & SD \\
\hline Age & 60.94 & 11.17 & 59.17 & 9.61 \\
Body Mass Index & 28.44 & 5.60 & 27.10 & 4.99 \\
\hline
\end{tabular}

The mean age for female is 60.9 and standard deviation 11.17, while the mean age for male is 59.17 and standard deviation 9.61.The mean of Body Mass Index for female is 28.44 and standard deviation 5.60, for male the mean of Body Mass Indexis 27.10 and standard deviation is 4.99.

\subsection{Wound Infection Outcomes Among the Studied Samples $n=120$}

Table 3. Wound infection outcomes.

\begin{tabular}{|c|c|c|c|c|c|c|}
\hline \multirow{2}{*}{ Wound infection } & \multicolumn{2}{|c|}{ Male $(n=104)$} & \multicolumn{2}{|c|}{ Female $(n=16)$} & \multicolumn{2}{|c|}{ Total $(n=120)$} \\
\hline & n & $\%$ & $\mathbf{n}$ & $\%$ & $\mathrm{n}$ & $\%$ \\
\hline $\begin{array}{l}\text { Superficial Leg } \\
\text { Infection }\end{array}$ & 0 & 0.0 & 1 & 6.3 & 1 & 0.8 \\
\hline $\begin{array}{l}\text { Superficial } \\
\text { Sternum Infection }\end{array}$ & 5 & 4.8 & 1 & 6.3 & 6 & 5 \\
\hline $\begin{array}{l}\text { Deep Leg } \\
\text { Infection }\end{array}$ & 0 & 0.0 & 0 & 0.0 & 0 & 0.0 \\
\hline $\begin{array}{l}\text { Deep Sternum } \\
\text { Infection }\end{array}$ & 3 & 2.9 & 1 & 6.3 & 4 & 3.3 \\
\hline Total & 8 & 7.7 & 3 & 18.9 & 11 & 9.1 \\
\hline
\end{tabular}

Superficial leg infection were measured in male $0.0 \%$ while measured in female $6.3 \%$. The superficial sternum infection were measured in male $4.8 \%$ while in female $6.3 \%$. The deep sternum infection were analyzed $2.9 \%$ among male while $6.3 \%$ in female. No any deep leg infection was measured for both male and female.

Table 4. Relationship between infected and non-infected cases related to selected patient's factors $(n=120)$.

\begin{tabular}{|c|c|c|c|}
\hline \multicolumn{4}{|l|}{ Patient's factors: } \\
\hline Characteristics & $\begin{array}{l}\text { Infected } \\
(n=10)\end{array}$ & $\begin{array}{l}\text { Non } \\
\text { infected)n=109) }\end{array}$ & $\begin{array}{l}P \text { - } \\
\text { Value }\end{array}$ \\
\hline & n $\%$ & n $\%$ & \\
\hline $\begin{array}{l}\text { Chronic obstructive } \\
\text { pulmonary diseases,n (\%) }\end{array}$ & $4(40)$ & $20(18.3)$ & .112 \\
\hline $\begin{array}{l}\text { Peripheral vein disease, } \mathrm{n} \\
(\%)\end{array}$ & $4(40)$ & $20(18.3)$ & .112 \\
\hline Diabetes Mellitus, n (\%) & $10(100)$ & $86(78.8)$ & .005 \\
\hline Current Smoking, n (\%) & $3(30)$ & $28(25.7)$ & .503 \\
\hline Hypertension, n (\%) & $9(90)$ & 98(89.9) & .704 \\
\hline
\end{tabular}

With regard to Chronic Obstructive Pulmonary Disease, $40 \%$ of the patients with surgical site infection reported to have had Chronic Obstructive Pulmonary Disease. However, 
the non infected cases recorded only $18.3 \%$ for Chronic Obstructive Pulmonary Disease. The peripheral vein disease was $40 \%$ prevalent among the surgical site infection cases while its prevalence rates among the non infected patients was $18.3 \%$. However, this did not imply a statistical association to the surgical site infection.

This is a considerable amount considering the percentage of smokers in the non infected population was $25.7 \%$.All the cases of surgical site infection also had reported to be diabetic $100 \%$ of the infections were reported among the patients with Diabetes Mellitus, while $78.8 \%$ of Diabetes Mellitus were reported as non infected cases. A two sided Fisher's exact tests revealed a strong association between Diabetes and the surgical site infection. About $30 \%$ of the infections were recorded among the patients who had also reported to be smokers. $90 \%$ of the surgical site infection cases were hypertension cases while the prevalence of hypertension among the non infected cases was $89.9 \%$. Their relationship for the prevalence of hypertension and surgical site infection was weakly presented by the data.

Table 5. Relationship between infected and non infected cases related to selected preoperative factors $(n=120)$.

\begin{tabular}{llll}
\hline Preoperative factors & Infected(n=10) & $\begin{array}{l}\text { Non infected } \\
(\mathbf{n = 1 0 9 )}\end{array}$ & $\boldsymbol{P}$-Value \\
\hline \multicolumn{1}{c}{$\mathbf{n \%}$} & $\mathbf{n} \%$ & \\
\hline Methicillin-resistant & $0(0)$ & $2(2)$ & $.000^{*}$ \\
Staphylococcus aureus, n (\%) & $3(30)$ & $57(52)$ & .322 \\
Clipper, n (\%) & $1(10)$ & $13(12)$ & 1.000 \\
Razor, n (\%) & $8(80)$ & $81(74)$ & 1.000 \\
Pre bath, n (\%) & $10(100)$ & $10(100)$ & \\
Antibiotic, n (\%) & &
\end{tabular}

(* statistically significant $<0.05$ )

* $P$ values are calculated using the Student $t$ test and Fisher's exact test

*All percentages were calculated by using the denominators which excluded the missing values in infected cases.

*Responses are not mutually exclusive.

\section{Preoperative factors}

There were no cases of Methicillin-resistant Staphylococcus aureus among the surgical site infection cases and only existed 2 cases in the non infected cases. 30\% of infected cases found to have used clipper while $52 \%$ of the non infected cases. The analyses revealed a weak association between the use of the clipper and the surgical site infection among the King Abdulaziz University Hospital of coronary artery bypass graft patients. About $10 \%$ of the surgical site infection cases reported to have used a razor while $12 \%$ of the non infected cases was reported to have used the razor. $80 \%$ of the surgical site infection cases had recorded being bathed prior to the procedure and only $74 \%$ percent of the non infected cases recorded pre bathing. In this study, there was a weak association between these variable and the incidences of the surgical site infection. The analyses revealed all coronary artery bypass graft patients, both the surgical site infected and non-infected cases had in fact used antibiotics and therefore analyzing the statistical significance was not possible.
Table 6. Relationship between infected and non-infected cases related to selected intraoperative risk factors $(n=120)$.

\begin{tabular}{llll}
\hline $\begin{array}{l}\text { Intraoperative } \\
\text { factors }\end{array}$ & Infected (n=10) & Non infected (n=109) & $\boldsymbol{P}$ - Value \\
\hline & $\mathbf{n} \%$ & $\mathbf{n} \%$ & \\
\hline Urgency, n (\%) & $1(10)$ & $2(2)$ & .134 \\
Elective, n (\%) & $8(80)$ & $104(95)$ & .13 \\
Emergency, n (\%) & $1(10)$ & $4(4)$ & .36 \\
Antibiotic, n (\%) & $10(100)$ & $10(100)$ & \\
\hline
\end{tabular}

(* statistically significant $<0.05$ )

* $P$ values are calculated using the Student $t$ test and Fisher's exact test.

* All percentages were calculated by using the denominators which excluded the missing values in infected cases.

* Responses are not mutually exclusive.

The analyses revealed that the relationship between the urgency of the procedure and the prevalence of the surgical site infection was not statistically significant $(p=.134)$. Only $10 \%$ of the surgical site infection cases underwent an urgent procedure and just 2 in the non infected cases, constituting of about $2 \%$. The analysis revealed that the relationship between the elective procedure and the surgical site infection was not statistically significant, $(p=.13)$. About 80 percent of the surgical site infection cases were elective cases while about $95 \%$ of the non infected were elective cases. Whether the procedure was an emergency was also found to have little effect on the surgical site infection. The relationship between the emergency procedure and the surgical site infection was also not statistically significant $(p=.36)$, the statistical analysis of antibiotic was not significance.

Table 7. Relationship between infected and non-infected cases related to selected post-operative risk factors $(n=120)$.

\begin{tabular}{|c|c|c|c|}
\hline Post-operative factors & $\begin{array}{l}\text { Infected } \\
(n=10)\end{array}$ & $\begin{array}{l}\text { Non infected } \\
(n=109)\end{array}$ & $P$-Value \\
\hline & n $\%$ & n \% & \\
\hline $\begin{array}{l}\text { Re-operation for bleeding, } \\
\mathrm{n}(\%)\end{array}$ & $1(10)$ & $3(3)$ & .299 \\
\hline Rewiring, n (\%) & $6(60)$ & $0(0)$ & $.000 *$ \\
\hline Antibiotic, n (\%) & $10(100)$ & $110(100)$ & \\
\hline Dressing, $\mathrm{n}(\%)$ & $10(100)$ & $0(0)$ & $.000 *$ \\
\hline Ventilation, $\mathrm{n}(\%)$ & $4(40)$ & $0(0)$ & $.000 *$ \\
\hline Low Cardiac output, n (\%) & $2(20)$ & $1(1)$ & $.018^{*}$ \\
\hline \multicolumn{4}{|l|}{ Others: } \\
\hline $\begin{array}{l}\text { Length of ICU stay, (n, } \\
\text { mean, SD) }\end{array}$ & $10,4.5,1.4$ & $\begin{array}{l}110,14.3 \\
2.57\end{array}$ & .441 \\
\hline $\begin{array}{l}\text { Length of Day/Days in } \\
\text { Hospital, (n, mean, SD) }\end{array}$ & $\begin{array}{l}10,15.9 \\
19.2\end{array}$ & $110,3.9 .97$ & .119 \\
\hline
\end{tabular}

(* statistically significant $<0.05$ )

*All percentages were calculated by using the denominators which excluded the missing values.

* Responses are not mutually exclusive.

Only $10 \%$ of the surgical site infection cases had been reoperated for bleeding while just 3\% of the non infected cases had been re-operated for bleeding. The p-value for the association was. 299. About $60 \%$ of the surgical site infectioncases had undergone the rewiring while among the non infected cases, none underwent the procedure. Fisher's exact tests reveal a strong association between rewiring and surgical site infection, with a p-value of.000. The analyses 
revealed all coronary artery bypass graftpatients, both the surgical site infection cases and the non infected cases had in fact used antibiotics and therefore analyzing the statistical significance was not possible. It study hypothesizes that improper wound cleaning and dressing is a contributing factor towards the wound infection of the surgical sites. There is found significant in influencing the surgical site infection since $100 \%$ of the surgical site infection cases were dressed and none of the non infected cases had been dressed. The relationship here is strong and the $\mathrm{P}$-value is. $000<0.05$

$40 \%$ of the surgical site infection cases reported to have had ventilation, whereas none of the non infected cases reported of the same. There was statistical significance of an association between ventilation and the prevalence of the surgical site infection, with the Fisher's exact tests giving a p-value of.000. Ventilation and dressing were found to have a strong association towards surgical site infection. The pvalues for ventilation and dressing were .000 and .000 respectively. There was a significant evidence to show a strong relationship between low cardiac output and surgical site infection, with $P=0.018<0.05$. The instances of low cardiac output among the surgical site infection cases was $20 \%$ while among the non infected cases, it was just $1 \%$.

The analyses revealed that the average number days surgical site infection cases stayed in Intensive Care Unitwas 4 and half days with a standard deviation of 1.4 , whereas the non infected cases stayed in intensive care unit for averagely 14.3 days with a standard deviation of 2.57 days. The statistical association between the length of stay in Intensive Care Unit and the infections in the surgical sites was weak. In Length of Day/Days in Hospital, the analyses revealed a weak association between the two variables with the $p$-value of 119 .

\section{Discussion of Major Findings}

The discussion involves the provision of the new research questions that the study raises as well as the implications of the research for practice [15]. In addition, it is required to contrast with finding of a study with previous studies to reach concise conclusions that can be used for evidence-based practice [16]. The aim of this study was to evaluate risk factors associated with surgical site infection among coronary artery bypass graft patients and to assess the nurses compliance to bundle care to prevent surgical site infection.

\subsection{Demographic Characteristic}

The finding of the data analyzed in table 1 showed that all female patients in this study were non-Saudis. There is no previous study that investigated nationality as a potential risk factor in Saudi Arabia. This research is the only research within the last four years which focused on prevalence of the surgical site infection among the coronary artery bypass graft patients in Saudi Arabia. However, a previous population-based cohort study by [17] reported the prevalence of the surgical site infection among the coronary artery bypass graft patients in the Saudi Arabia in terms of their race. However, in this study, the results presented that surgical site infection is more common among non-Saudis than Saudis coronary artery bypass graft patients. Therefore, further research should be examined to verify the importance of nationality in predicting the prevalence of surgical site infection among coronary artery bypass graft patients living Saudi Arabia.

Table 2 shows the mean age reported for females was $(M=60.9)$ and a standard deviation $(S D=11.17)$, while the mean age among male was $(M=59.17)$ and standard deviation $(S D=9.61)$. This result is compatible with the findings of the previous studies, which reported that the average age for the development of SSI among the coronary artery bypass graft patients was 60 to 72 years[18].

Different study by [19]. reported that the most patients were males $(78.4 \%)$ within $58-73$ years bracket with average age of 66 years, which is slightly higher than that presented in [18]. However, like presentation from previous research, the results presented by this study shows that advanced age above 60 years is a risk factor surgical site infection among coronary artery bypass graft patients.

The body mass index, the mean for females was $(M=28.44)$ and standard deviation $(S D=5.60)$, while among male, the mean of body mass index was $(M=27.10)$ and standard deviation $(S D=4.99)$. The World Health Organization classifies an individual with a body mass index of 25 or above as being overweight while a person with abody mass index of 30 is considered obese[20]. Therefore, this study shows that an increase in body weight increases also the risk of surgical site infection among coronary artery bypass graft patients. Similarly, recorded that an increased body mass index above 35 is a predictor of surgical site infection among the coronary artery bypass graft patients [19]. Therefore, this study established that increased body mass index, especially which is above 25 , is a risk factor for surgical site infection among coronary artery bypass graft patients in Saudi Arabia.

\subsection{Wound Infection Outcomes}

With regards to outcomes of wound infection in table 3 shows that no male had superficial leg infection, $6.3 \%$ of the female participants had this infection. Superficial sternum infection was recorded at $4.8 \%$ males and $6.3 \%$ of the female participants. $2.9 \%$ of the males and $6.3 \%$ female had deep sternum infection. Finally, no any deep leg infection was measured for both male and female. The rates recorded of $1.7 \%, 1.2 \%$, and $0.6 \%$ for sternal, superficial internal and deep sternal leg infections, respectively [21]. Previous studies had indicated that wound infections varied and depended on whether the wound was clean or not and was not entirely dependent on the gender of participants, but the nature of dressing done after operation[22, 21]. plain dressing, or in other cases plain postoperative gauze dressing with sterilization, was seen as effective methods in helping reduce chances of infections [21]. 


\subsection{Relationship Between Infected and Non-infected Cases Related to Selected Patient's Factors}

Table 4shows that Chronic Obstructive Pulmonary Disease: Among all sampled patients in this study, $40 \%$ had a history of Chronic Obstructive Pulmonary Disease with infected cases and $18.3 \%$ non-infected cases. Chronic Obstructive Pulmonary Disease is a significant risk factor because it weakens the immune system by causing airway inflammation, and obstruction and destruction of epithelium, leading to increased incidences of pneumonia, acute myocardial infarction, and acute respiratory failure [23]. Chronic Obstructive Pulmonary Disease also increases the risk of developing deep sternum wound infection and has higher morbidity and mortality rates for patients undergoing coronary artery bypass graft surgery [24].

Peripheral Vascular Disease: It is another significant risk factor for patients undergoing coronary artery bypass graft surgery. Peripheral Vascular Disease affects peripheral blood vessels causing atherosclerosis. In this study, $40 \%$ Peripheral Vascular Disease infected cases were recorded, while the non-infected cases were $18.3 \%$. There was plague build up of fatty materials on the inner walls of the lower extremity arteries, abdominal aorta, and iliac [25].

Also indicate that the spread of Peripheral Vascular Disease is equal between female and male patients. This risk of Peripheral Vascular Disease increases with every decade of life after 40 years. It is more prevalent in patients older than 70 years or 50 years with a history of smoking, or patients diagnosed with diabetes [25].

Diabetes Mellitus: In this study, the infected cases were $100 \%$ while in non-infected cases were $78.8 \%$. These findings are comparable to indicate diabetes is prevalent in both female and male coronary artery bypass graft patients [26]. Diabetes Mellitus is a risk because it increases the risk of atherosclerosis disease and exaggerated neointimal hyperplasia, which leads to increased chances of repeat vascularization and stroke [26]. High glucose and insulin levels also inflict injury and impede repair in vascular tissues, causes coronary atherosclerosis, and requires long-term preoperative monitoring [27].

Smoking: The infected cases were reported 30\%while among non infected cases were $25.7 \%$. [28] found a much higher percentage of smokers among patients undergoing coronary artery bypass graft surgery: male (59.9\%) and females $(40 \%)$. However, the study recruited a young cohort of below 40 years of age, which could explain the higher percentages of smokers. However, study in New Zealand found more women (20.2\%) smokers among patients undergoing coronary artery bypass graft surgery compared to male patients (13.1\%) [29]. Smoking is a significant risk factor leading to the advancing of surgical site infection and other risk factors such as myocardial infarction, reoperation, and angina pectoris [28].

Hypertension: It is the most significant risk factor common to $90 \%$ in infected cases while in non infected cases were
$89.9 \%$ of all sampled patients who had undergone coronary artery bypass graft surgery. In line with this findings, the hypertension affects $80 \%$ of patients undergoing coronary artery bypass graft surgery [30]. Therefore, hypertension is a significant co-morbidity for coronary artery disease. For patients undergoing coronary artery bypass graft surgery, it leads to adverse outcomes such as bleeding complications, left ventricular or cerebral vascular dysfunction and renal insufficiency or failure for both male and female patients [31]. Hypertension also predicts the higher rates of morbidity and mortality among female patients undergoing coronary artery bypass graft surgery $[32,33]$.

\subsection{Relationship Between Infected and Non-infected Cases Related to Selected Preoperative Risk Factors}

The finding of the data analyzed as shown in table 5 the significant preoperative risk factor is a bacterial infection caused by Methicillin-Resistant Staphylococcus Aurous. All the sampled patients were cultured and the results were negative for Methicillin-Resistant Staphylococcus Aurous. This finding is against that of study (2014),indicated that Methicillin-Resistant Staphylococcus Aurous is one of the common pathogens causing infection for $14.6 \%$ of all surgical sites, $20 \%$ of all sternal site infections and increases the length of hospital stay for all patients after coronary artery bypass graft [19].Similarly, with this finding that Methicillin-Resistant Staphylococcus Aurous causes deep sternum infections and proposes preoperative Methicillin-Resistant Staphylococcus Aurous culturing as important to prevent infections and associated high morbidity and mortality rates [34].

Clippers/Razors: The preoperative risk factor for patients undergoing coronary artery bypass graft surgery was preoperative removal of hair. In this study, 30\% of infected cases and $52 \%$ of non infected cases for patients used clipper, but the infected cases using razors were $10 \%$ while in non infected cases $12 \%$. This finding agreed with that of previous study (2014), that indicated $94 \%$ of medical centers use clippers for hair removal. The use of clippers to accomplish hair removal is safer because they have a lower surgical site infection rates compared to the use of razors [35].

Preoperative Bathing: Another risk factor was preoperative bathing (pre-bath) or the lack of it. Nurses are responsible for taking care of patients during preoperative phase. In the given study, the infected cases were $80 \%$, while non infected cases were $74 \%$ of the sample patients. Around $94 \%$ of medical centers use standardized pre-bath protocols for patients with previous Methicillin-Resistant Staphylococcus Aurous infections, for high-risk patients and for all other patients. Prebath minimizes bacterial colonization and to prevent deep wound infection [35]. Antibiotic: Administration of antibiotic is important to decrease the risk of infection. Antibiotics were administered to all sampled coronary artery bypass graft patients. Antibiotics reduce surgical site infection by minimizing bacterial colony counts [35]. 


\subsection{Relationship Between Infected and Non-infected Cases Related to Selected Intraoperative Risk Factors}

The finding of data analyzed as shown in table 6 the type of Surgery: In this study, the infected cases were $10 \%$ while the non infected cases $2 \%$ in urgency surgery. In the elective surgery, the infected cases were $80 \%$, while the non-infected cases recorded $95 \%$ of the cases. The infected cases in emergent surgery were $10 \%$ while in non-infected cases were $4 \%$. An increase of urgent and emergent coronary artery bypass graft surgery at $51.6 \%$ [36]. Patients undergoing urgent and emergent coronary artery bypass graft surgery have a greater likelihood of developing comorbidities such as obesity, diabetes, hypertension, renal failure, and cerebrovascular disease than patients undergoing elective surgery [36]. In most cases, urgent and emergent surgery are carried out when the patient condition has worsened compared to elective surgery that the patient makes a conscious decision to undergo surgery [36].Antibiotics: Other intraoperative risk factors were the use or absence of antibiotics and administration of inotropes. In this study, all male and female patients received antibiotics. All medical centres $(100 \%)$ use antibiotics to reduce bacterial colony counts. Patients who do not receive antibiotics are at a greater risk of developing surgical site infection [35].

\subsection{Relationship Between Infected and Non-Infected Cases Related to Select Postoperative Risk Factors}

The finding of data analyzed as shown in table 7 the reoperation it is a significant postoperative risk factor. Reoperation refers to redoing coronary artery bypass graft surgery [37]. In this study the infected cases were $10 \%$ while in non infected cases were 3\%. Also a lower number of coronary artery bypass graft surgery patients $(10 \%$ to $20 \%)$ require reoperation [37]. However, a higher percentage $(36.7 \%)$ of coronary artery bypass graft surgery patients undergo reoperations, which is prevalent among smokers and patients with acute coronary syndrome, diabetes mellitus, hypertension and family history of coronary artery disease [38]. Reoperation is a risk factor leading to higher rates of mortality because of a greater likelihood of developing perioperative myocardial infarction and low cardiac output [39]. Rewiring: It is a postoperative coronary artery bypass graft procedure used to stabilize sternum, usually following deep sternum infection. It is a significant risk factor for coronary artery bypass graft patients. In this study, $60 \%$ of infected cases comprise $0.0 \%$ of non-infected cases. Findings are confirmed with previous study was in 2015 that compared coronary artery bypass graft patients who used arterial grafts from Right Internal Mammary Artery versus Radial Artery, which found $2.9 \%$ of Right Internal Mammary Artery patients and $4.7 \%$ of Radial Artery patients needed rewiring [40]. However, this study's findings were inconsistent with those of last study in 2014 that found 50\% of patients undergoing Vacuum Assisted Closure needed rewiring but no patients receiving flap needed rewiring [41].
Antibiotics: The type of antibiotics applied to reduce postoperative superficial and deep wound infection could be a risk factor to patients who have undergone coronary artery bypass graft. In this study, $100 \%$ of the infected cases and $100 \%$ of non-infected cases used antibiotics. These results support of the last study in 2014 that found $10 \%$ of patients having conventional wound dressing received antibiotics, but none of the patients who received negative pressure wound therapy [42]. And $92.3 \%$ of the patients receiving negative pressure wound therapy heal without complications, eliminating the need for antibiotics compared to $77.5 \%$ receiving conventional dressing [42].

Dressing: This study finds the infected cases were $100 \%$ while $0.0 \%$ non infected cases. This study's findings are comparable to previous study 2014 that compared negative wound pressure dressing to conventional dressing [42]. A fewer number of patients required dressing. However, different types of dressing and the duration of dressing pose different levels of risk to coronary artery bypass graft patients. In negative pressure dressing, $7.5 \%$ of patients had complications in wound healing compared to $25 \%$ of patients using conventional wound dressing [42]. Mechanical Ventilation: It is another significant postoperative risk factor affecting patient undergoing coronary artery bypass graft surgery. In the given study, the infected cases were $40 \%$ with $0.0 \%$ of non infected cases. The indication $7 \%$ of patients undergoing coronary artery bypass graft receive mechanical ventilation for 24 to 30 hours [43]. The study also indicates that female patients have a longer mean duration of mechanical ventilation (19.8 hours) compared to male patients (16.2 hours). The independent risk factors for prolonged mechanical ventilation were old age and female gender. In slightly different findings indicate a smaller percentage of coronary artery bypass graft patients $(2.3 \%)$ require prolonged ventilation ( $>25$ hours), but with no significant difference between male and female patients [44].

Low Cardiac Output: It is another significant postoperative risk factor. Low Cardiac Output is a condition where the heart is not pumping enough blood at each heartbeat. For this study, the infected cases were $20 \%$ while non-infected cases were $1 \%$. These findings support those of study in 2014indicate that $3 \%$ of coronary artery bypass graft patients exhibit low cardiac output syndrome [45]. Low cardiac output affects a much higher percentage $(13.5 \%)$ of patients undergoing coronary artery bypass graft surgery with old age, impaired left ventricular function, and emergence and incomplete revascularization being independent risk factors [46]. Length of stay: The study also established that the length of intensive care unit stay and days in the hospital after grafting is insignificant risk factors of surgical site infection in coronary artery bypass graft patients. Also a number of previous studies had shown that pre-operative stays were insignificant risk factors for surgical site infection [18]. 


\section{Implication of Study}

As related to nursing practice, the evaluate risk areas that should be of concern to any nursing professional. The implication is that a nursing professional need to be aware of these risk factors and on approaches to the reduction of the risk factors to promote health consequences for patients processed coronary artery bypass graft. In the nursing implication related to administration theory they need to implement all association for professionals in infection control theoretical frameworks in which all domains of the competency model should be directed towards minimization of the risk factors. The leadership, technological domain, performance improvement, and infection prevention domain should have policies geared towards minimizing the mentioned risks. The study should be used to inform each of the domains on the focus areas with regards to policy improvement.

The implications to the nursing education are similar such that the education process should emphasize on the risk factor areas and how to manage the risk, and creating informed nurses. Novice nurses need to continue professional development education program needed on all three levels of novices, professional and expert. On novice level, infection control practices should be informed to establish common ground to prevent surgical site infection on professional level. The use on the current edge of evidence based practices should be exploited and utilized as applicable. On expert level, integrating evidence into other models domains such as the technical domain, infection prevention and control domain, performance improvement and implementation domain and finally leadership and programmed management domain. In the nursing research, a potential of areas of concern to be researched were related to the nurses preparation of patients during perioperative period and adherences of surgical site infection bundle.

\section{Conclusion and Recommendation}

The findings of the research have been presented based on the demographic data and indicated that patients with higher weights and those diagnosed as obese are at an increased risk of suffering from the surgical site infection when undergoing surgical intervention for coronary artery bypass graft. The study established that bundle was proven to be effective in reducing risk factors to surgical site infection, however nurses adherence to surgical site infection bundle care were in complete and required more enforcement to comply.

The present study recommends for further research needs to focus on each risk factor and the approaches taken to minimizing these risks. The nursing recommendation on administration and organization policy, more studies on the applicability of the association for professionals in infection control framework is recommended to be applied in acute care setting, where it subdivides the organization into different domains that can easily be addressed. Dissemination of information regarding performance, improvement and implementation to surgical site infection care bundle requires clear administrative policy to ensure compliance to infection and prevention guidelines. In nursing practices recommendations, nurses should be diligent when it comes to evaluate the risk factors associated with coronary artery bypass graft patients. The risk factors have been classified from pre-operative to postoperative, and this should guide the implementation of association for professionals in infection control; a care framework that seeks to minimize these risks. Nurses should be aware of the importance of following surgical site infection bundles. Nurses should not only be educated on the importance of the bundles, but on how effective apply the bundles at different stages.

\section{References}

[1] Roger, V. L., Go, A. S., Lloyd-Jones, D. M., Benjamin, E. J., Berry, J. D., Borden, W. B...\& Turner, M. B. (2012). Heart disease and stroke statistics 2012 update: A report from the American Heart Association. Circulation, 125, e2-e220. doi: 10. 1161/CIR. 0b013e31823ac046.

[2] Osman, A. M., Alsultan, M. S., \& Al-Mutairi, M. A. (2011). The burden of ischemic heart disease at a major cardiac center in Central Saudi Arabia. Saudi Medical Journal, 32(12), 1279-1283.

[3] Sá, M. P.,Soares, E. F.,Santos, C. A.,Figueiredo, O. J.,Lima, R. O.,Escobar, R. R.,de Rueda, F. G.,\& Lima, R. C. (2011). Risk factors for mediastinitis after coronary artery bypass grafting surgery. Rev Bras Cir Cardiovasc, 26(1), 27-35.

[4] Lola, I., Levidiotou, S., Petrou, A., Arnaoutoglou, H., Apostolakis, E., \& Papadopoulos, G. S. (2011). Are there independent predisposing factors for postoperative infections following open-heart surgery? Journal of Cardiothoracic Surgery, 6, 151-167.

[5] Watson, D. S. (2009). National patient safety goals and implementation. AORN Journal, 90, 123-127.

[6] Graf, K., Ott, E., Vonberg, R. P., Kuehn, C., Haverich, A., \& Chaberny, I. F. (2010). Economic aspects of deep sternal wound infections. European Journal of Cardiothoracic Surgery, 37, 893-896.

[7] Bratzler, D. W., Dellinger, E. P., Olsen, K. M., Perl, T. M., Auwaerter, P. G., Bolon, M. K., Fish, D. N... \&Weinstein, R. A. (2013). Clinical practice guidelines for antimicrobial prophylaxis in surgery. American Journal of Health System Pharmacy, 70(3), 195-283.

[8] Julie D Lankiewicz, Deborah S Yokoe, Margaret A Olsen.(2013). Beyond 30 Dayes: Dose limiting the duration of surgical site infection follow up limit detection?. Journal of National Institutes of Health. 33, (2):202-204.

[9] Gould D (2012) Causes, prevention and management of surgical site infection. Nursing Standard. 26, 47, 47-56.

[10] Al-Zaru, I. M., Abu Al Rub, R., \& Musallam, E. A. (2011). Economical and clinical impact of surgical site infection following coronary artery bypass graft surgery in north Jordan. International Journal of Nursing Practice, 17(2), 117-125.

[11] Young MH, Washer L, \& Malani PN. (2008). Surgical Site Infections in Older Adults. Drugs Aging, 25 (5): 399-414. 
[12] Van der Slegt J, Romme J et al. (2013). Implementation of a Bundle of Care to Reduce Surgical Site Infections in Patients Undergoing Vascular Surgery. PLOS journal. pone, 0071566.

[13] Logan, S.,Quinn, D.,Brault, D.,Vandal, V.,Paré, B.,\& Clarke, S. (2016). Risk Factors and Best Practices for the Prevention of Post-Cardiac Surgery Surgical Site Infections in a Tertiary Care Centre. Canadian Journal of Cardiovascular Nursing, 26(4), 19-26. p-24.

[14] Murphy, D., Hanchett, M., Olmsted, R., Farber, M., et al. (2013). competency ininfection prevention: A conceptual approach to guide current and future practice. American Journal of Infection Control, 40(4), 296-303).

[15] Du Prel, J. -B.,Röhrig, B.,\& Blettner, M. (2009). Critical appraisal of scientific articles: part 1 of a series on evaluation of scientific publications. Deutsches Arzteblatt International, 106(7), 100-105. http://doi. org/10. 3238/arztebl. 2009. 0100.

[16] Martha S. Tingen, Anna H. Burnett, Rachel B. Murchison, H. Z. (2013). The Importance of Nursing Research. Journal of Nursing Education, 18(9), 1199-1216. http://doi. org/10. 3928/01484834-20090301-10.

[17] Alasmari, F. A.,Tleyjeh, I. M.,Riaz, M.,Greason, K. L.,Berbari, E. F.,Virk, A.,\& Baddour, L. M. (2012). Temporal Trends in the Incidence of Surgical Site Infections in Patients Undergoing Coronary Artery Bypass Graft Surgery: A Population-Based Cohort Study, 1993 to 2008. Mayo Clinic Proceedings, 87(11), 1054-1061. http://doi. org/10. 1016/j. mayocp. 2012. 05. 026.

[18] Korol, E.,Johnston, K.,Waser, N.,Sifakis, F.,Jafri, H. S.,Lo, M.,\& Kyaw, M. H. (2013). A Systematic Review of Risk Factors Associated with Surgical Site Infections among Surgical Patients. PLoS ONE, 8(12), e83743. http://doi. org/10. 1371/journal. pone. 0083743 .

[19] Si, D., Rajmokan, M., Lakhan, P., Marquess, J., Coulter, C., \& Paterson, D. (2014). Surgical site infections following coronary artery bypass graft procedures: 10 years of surveillance data. BMC Infectious Diseases, 14(1), 318. http://doi. org/10. 1186/1471-2334-14-318.

[20] World Health Organization. (2015). Obesity and overweight. Retrieved January 14, 2016, from http://www. who. int/mediacentre/factsheets/fs311/en/

[21] Gaspard, F., Brassard, P., Alam, T., Robineau, C., Page, C., Dell'Aniello, S., \& de Varennes, B. (2013). Impact of an antimicrobial dressing in reducing surgical site infections in cardiac surgery patients. Wounds: A Compendium of Clinical Research andPractice, 25(7), 178-185. Retrievedfrom http://www. woundsresearch. com/article/impactantimicrobial-dressing-reducing-surgical-site-infectionscardiac-surgery-patients.

[22] King, C., Aylin, P., Moore, L. S. P., Pavlu, J., \& Holmes, A. (2014). Syndromic surveillance of surgical site infections-a case study in coronary artery bypass graft patients. Journal of Infection, 68(1), 23-31. http://dx. doi. org/10. 1016/j. jinf. 2013.08. 017.

[23] Ho, C. H., Chen, Y. C., Chu, C. C., Wang, J. J., \& Liao, K. M. (2016). Postoperative Complications After Coronary Artery Bypass Grafting in Patients With Chronic Obstructive Pulmonary Disease. Medicine, 95(8), e2926. doi: 10. 1097/MD. 0000000000002926.

[24] Diodato, M., \& Chedrawy, E. (2014). Coronary Artery Bypass
Graft Surgery: The Past, Present, and Future of Myocardial Revascularisation. Surgery Research and Practice, 1-6.

[25] Savji, N., Rockman, C. B., Skolnick, A. H., Guo, Y., Adelman, M. A., Riles, T., \& Berger, J. S. (2013). Association between advanced age and vascular disease in different arterial territories: a population database of over 3 . 6 million subjects. Journal of the American College of Cardiology, 61(16), 1736-1743. doi:10. 1016/j. jacc. 2013. 01.054.

[26] Bangalore, S., Toklu, B., \& Feit, F. (2014). Outcomes With Coronary Artery Bypass Graft Surgery Versus Percutaneous Coronary Intervention for Patients With Diabetes Mellitus Can Newer Generation Drug-Eluting Stents Bridge the Gap? Circulation: Cardiovascular Interventions, 7(4), 518-525. doi: 10. 1161/CIRCINTERVENTIONS. 114. 001346.

[27] Hoffman, D. M., \& Tranbaugh, R. F. (2014). Coronary artery bypass graft (CABG) and the diabetic patient: Current perspectives. Research Reports in Clinical Cardiology, 4(5), 56-67. doi:10. 2147/RRCC. S39994.

[28] Uncu, H., Acipayam, M., Altinay, L., Dogan, P., Davarc1, I., \& Ozsoyler, I. (2014). The effect of gender on the early results of coronary artery bypass surgery in the younger patients' group. Brazilian Journal of Cardiovascular Surgery, 29(4), 569-573. doi: 10. 5935/1678-9741. 20140050.

[29] Wang, T. K. M., Ramanathan, T., Stewart, R., Gamble, G., \& White, H. (2013). Higher mortality in women undergoing coronary artery bypass grafting. New Zealand Medical Journal, 126(1387), 25-31. Retrievedfrom https://www. nzma. org. nz/_data/assets/pdf_file/0010/34120/content.pdf.

[30] Acton, Q. A. (Eds.). (2013). Hypertension: New Insights for the Healthcare Professional: 2013 Edition. Atlanta, Georgia: Scholarly Editions.

[31] Chaudhury, S., Saini, R., Bakhla, A. K., \& Singh, J. (2016). Depression and Anxiety following Coronary Artery Bypass Graft: Current Indian Scenario. Cardiology Research and Practice, 1-6. doi:10. 1155/2016/2345184.

[32] Alam, M., Lee, V. V., Elayda, M. A., Shahzad, S. A., Yang, E. Y., Nambi, V.,...\& Ramanathan, K. B. (2013). Association of gender with morbidity and mortality after isolated coronary artery bypass grafting. A propensity score matched analysis. International Journal of Cardiology, 167(1), 180184. doi:10. 1016/j. ijcard. 2011. 12. 047.

[33] Arifi, A. A., Ahmad, M., Van Onselen, R., \& Najm, H. K. (2014). Prevalence and impact of carotid disease in adult Saudi patients undergoing isolated coronary artery bypass surgery on early postoperative outcome. European Heart Journal Supplements, 16(suppl B), B44-B48. doi:10. 1093/eurheartj/suu021.

[34] Bryan, C. S., \& Yarbrough, W. M. (2013). Preventing deep wound infection aftercoronary artery bypass grafting: a review. Texas Heart Institute Journal / from theTexas Heart Institute of St. Luke's Episcopal Hospital, Texas Children's Hospital, 40(2), 125-39. Retrievedfrom http://www. pubmedcentral. nih. gov/articlerender. fcgi?artid=3649789\&tool=pmcentrez\&rendertype=abstract.

[35] Injean, P., McKinnell, J. A., Hsiue, P. P., Vangala, S., Miller, L. G., Benharash, P., ... Gregson, A. L. (2014). Survey of Preoperative Infection Prevention for Coronary Artery Bypass Graft Procedures. Infection Control \& Hospital Epidemiology, 35(06), 736-737. http://doi. org/10. 1086/676435. 
[36] Ghanta, R. K., Kaneko, T., Gammie, J. S., Sheng, S., \& Aranki, S. F. (2013). Evolving trends of reoperative coronary artery bypass grafting: an analysis of the Society of Thoracic Surgeons Adult Cardiac Surgery Database. The Journal of Thoracic and Cardiovascular Surgery, 145(2), 364-372. doi:10. 1016/j. jtcvs. 2012. 10. 051.

[37] Katlandur, H., Ulucan, S., Keser, A., Kaya, Z., \& Tuncez, A. (2013). Reoperative coronary artery bypass grafting. Journal of Clinical and Experimental Investigations, 4(3), 380-382. doi: 10. 5799/ahinjs. 01. 2013. 03. 0308.

[38] Inci, S., Arslan, S., Bakirci, E. M., Tas, M. H., Gundogdu, F., \& Karakelleoglu, S. (2014). Predictors of reintervention after coronary artery bypass grafting. European Review for Medical and Pharmacological Sciences, 18, 66-70.

[39] Al - Jughiman, M., Algarni, K., \& Yau, T. (2015). Outcomes of Isolated Reoperative Coronary Artery Bypass Grafting in Elderly Patients. Journal of Cardiac Surgery, 30(1), 41-46. doi:10. 1111/jocs. 12468.

[40] Raja. G. Benedetto. U. Charles D. (2015). Multiple arterial grafting confers survival advantage compared to percutaneous intervention with drug-eluting stents in multivessel coronary artery disease: A propensity score adjusted analysis. International Journal of Cardiology. http://dx. doi. org/10. 1016/j. ijcard. 2015. 04. 059.

[41] Badr-Eddin, M. F., Rouchdy, A. M., \& Hussien, M. A. (2014). Vacuum assisted closure versus omental flap in management of mediastinitis after cardiac surgery. Journal of the Egyptian Society of Cardio-Thoracic Surgery, 22(2), 1-6.
[42] Witt-Majchrzak, A., Zelazny, P., \& Snarska, J. (2014). Preliminary Outcome of Treatment of Postoperative Primarily Closed Sternotomy Wounds Treated Using Negative Pressure Wound Therapy. Polish Journal of Surgery, 86(10), 456-465. doi:10. 2478/pjs-2014-0082.

[43] Tawfiq, M. (2015). Impact of Preoperative Risk Factors upon Duration of Intubation for Cardiosurgery Patients in Ibn-AlBettarcenter. Kufa Journal for NursingSciences, 5(2), 1-9. Retrievedfrom http://uokufa. edu. iq/journals/index. $\mathrm{php} / \mathrm{kjns} /$ article/view/3932.

[44] Erdil, N., Gedik, E., Donmez, K., Erdil, F., Aldemir, M., Battaloglu, B., \& Yologlu, S. (2014). Predictors of postoperative atrial fibrillation after on-pump coronary artery bypass grafting: Is duration of mechanical ventilation time a risk factor? Annals of Thoracic and Cardiovascular Surgery, 20(2), 135-142. doi: 10. 5761/atcs. oa. 12. 02104.

[45] Kolat, P., Ried, M., Haneya, A., Philipp, A., Kobuch, R., Hirt, S. \& Diez, C. (2014). Impact of age on early outcome after coronary bypass graft surgery using minimized versus conventional extracorporeal circulation. Journal of Cardiothoracic Surgery, 9(143), 1-6. doi:10. 1186/s13019014-0143-3.

[46] Ding, W., Ji, Q., Shi, Y., \& Ma, R. (2015). Predictors of low cardiac output syndrome after isolated coronary artery bypass grafting. International Heart Journal, 56(2), 144-149. doi:10. 1536/ihj. 14-231. 